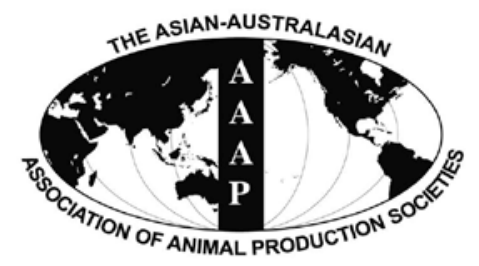

Asian-Aust. J. Anim. Sci.

Vol. 25, No. 2 : 177 - 182

February 2012

www.ajas.info

http://dx.doi.org/10.5713/ajas.2011.11308

\title{
Genetic Differentiation of Chinese Indigenous Meat Goats Ascertained Using Microsatellite Information
}

\author{
Y. H. Ling ${ }^{1,2,3}$, X. D. Zhang ${ }^{1,2}$, N. Yao ${ }^{3}$, J. P. Ding ${ }^{1,2, a}$, H. Q. Chen ${ }^{1,2}$, Z. J. Zhang ${ }^{1,2}$, \\ Y. H. Zhang ${ }^{1,2}$, C. H. Ren ${ }^{1,2}$, Y. H. Ma ${ }^{3}$ and X. R. Zhang ${ }^{1,2, a, *}$ \\ ${ }^{1}$ College of Animal Science and Technology, Anhui Agricultural University, Hefei 230036, China
}

\begin{abstract}
To investigate the genetic diversity of seven Chinese indigenous meat goat breeds (Tibet goat, Guizhou white goat, Shannan white goat, Yichang white goat, Matou goat, Changjiangsanjiaozhou white goat and Anhui white goat), explain their genetic relationship and assess their integrity and degree of admixture, 302 individuals from these breeds and 42 Boer goats introduced from Africa as reference samples were genotyped for 11 microsatellite markers. Results indicated that the genetic diversity of Chinese indigenous meat goats was rich. The mean heterozygosity and the mean allelic richness (AR) for the 8 goat breeds varied from 0.697 to 0.738 and 6.21 to 7.35 , respectively. Structure analysis showed that Tibet goat breed was genetically distinct and was the first to separate and the other Chinese goats were then divided into two sub-clusters: Shannan white goat and Yichang white goat in one cluster; and Guizhou white goat, Matou goat, Changjiangsanjiaozhou white goat and Anhui white goat in the other cluster. This grouping pattern was further supported by clustering analysis and Principal component analysis. These results may provide a scientific basis for the characteristization, conservation and utilization of Chinese meat goats. (Key Words : Meat Goat, Genetic Diversity, Genetic Differentiation, Microsatellite)
\end{abstract}

\section{INTRODUCTION}

The domestic goat (Capra hircus) is one of the most important livestock species in animal husbandry. China raises the largest number of goats in the world and has a valuable resource of goat breeds. There are more than 20 indigenous goat breeds in China, including goats for meat, wool, milk, mutton, and kid leather (Tu et al., 1989). Goats have a strong adaptability and are distributed in different environmental areas. There were several meat-type goat breeds in China. These meat goats, which are mainly distributed in the middle and southern regions of China, play an important role in the meat market.

Genetic diversity and relationships among some

\footnotetext{
* Corresponding Author : Xiaorong Zhang. Tel: +86-5515785928, Fax: +86-551-5785928, E-mail: zxr@ahau.edu.cn

${ }^{2}$ Local Animal Genetic Resources Conservation and Biobreeding Laboratory of Anhui Province, Hefei 230036, China.

${ }^{3}$ Institute of Animal Science, Chinese Academy of Agricultural Sciences, Beijing 100193, China.

a These authors contributed equally to this work and should be considered as corresponding author.

Received August 31, 2011; Accepted October 31, 2011
}

indigenous goat breeds in China have been studied using RFLP (Li et al., 1997; Zhao et al., 2011) and RAPD of genomic DNA (Li et al., 2000). In addition, there is some research on Chinese cashmere goats using SSR of genomic DNA (Di et al., 2010), but there is limited information regarding Chinese indigenous meat goats based on microsatellite markers.

In the past three decades, meat production performance has been the primary breeding objective. Genetic admixture among some breeds and inbreeding within the breeds is possible. This may have led to the loss of genetic structure and diversity in some of these breeds. Futhermore, some breeds have decreased rapidly in the number of sires and in population size such as seen in the shannan white and yichang white goats. Some breeds are even facing extinction.

In this study, efforts were made to evaluate genetic diversity and relationships of 7 Chinese indigenous meat goat breeds and an African goat breed based on standard microsatellite markers. The goal was to have a better understanding of current diversity and the level of inbreeding in these breeds, and offer a contribution towards further improvement of conservation schemes. 


\section{MATERIALS AND METHODS}

\section{Sample collection and DNA extraction}

Blood samples from 302 animals were collected from seven Chinese indigenous meat goat breeds (Table 1). Among these meat goat breeds, Tibet goats are dualpurpose meat and cashmere goats. The seven Chinese goat breeds come from seven different provinces, mainly distributed among the Yangtze River. Samples for the indigenous breeds were collected from their conservation farms. Additionally, we collected 42 Boer goats introduced from Africa as reference samples. Genomic DNA was extracted from all blood samples using a standard phenolchloroform extraction method (Sambrook et al., 2001).

\section{Microsatellite genotyping}

Eleven microsatellites were used from the panel recommended by ISAG/FAO for goat diversity studies (Table 2). Forward primers were 5'-labelled with fluorescent dyes (FAM or HEX). PCR amplifications were performed in $12 \mu \mathrm{l}$ reaction volumes containing $50 \mathrm{ng}$ of genomic DNA, $0.025 \mu \mathrm{M}$ of each primer, $250 \mu \mathrm{M}$ of each dNTP, 1.25 units of Taq polymerase and 1× Magnesium-
Table 1. Sampling information of the 7 Chinese goat breeds

\begin{tabular}{lcl}
\hline Breed name and index & Number & \multicolumn{1}{c}{ Collection location } \\
\hline Tibet goat (TB) & 45 & Changdu City, Tibet \\
Guizhou white goat (GZ) & 38 & Zunyi City, Guizhou \\
Shannan white goat (SN) & 48 & Ankang City, Shaanxi \\
Yichang white goat (YC) & 44 & Yichang City, Hubei \\
Matou goat (MT) & 42 & Changde City, Hunan \\
Changjiangsanjiaozhou & 46 & Nantong City, Jiangsu \\
$\quad$ white goat (CSJ) & & \\
Anhui white goat (AH) & 39 & Feidong county, Anhui \\
\hline
\end{tabular}

free PCR buffer (Takara, Japan). Amplifications were carried out using the GeneAmp PCR 9700 thermocycler (Applied Biosystems), with the following cycling parameters: $94^{\circ} \mathrm{C}$ for 5 min followed by 32 cycles of $94^{\circ} \mathrm{C}$ for $30 \mathrm{~s}$, annealing at 53 to $60^{\circ} \mathrm{C}$ for $30 \mathrm{~s}, 72^{\circ} \mathrm{C}$ for $30 \mathrm{~s}$, and a final step at $72^{\circ} \mathrm{C}$ for $8 \mathrm{~min}$. PCR products were diluted $1 / 3$ to $1 / 4$ and $0.75 \mu \mathrm{l}$ of each diluted product was then mixed with an internal standard $\left(G e n e S \operatorname{can}^{\mathrm{TM}}, 500 \mathrm{LIZ}^{\mathrm{TM}}\right.$, Applied Biosystems) according to the manufacturer's instructions. Genotyping was carried out on an ABI 3130xl automated capillary sequencer.

Table 2. Information of 11 microsatellite loci used in this study

\begin{tabular}{|c|c|c|c|c|c|c|}
\hline Locus & $\begin{array}{l}\text { Primer sequence } \\
\left(5^{\prime}-3^{\prime}\right)\end{array}$ & $\begin{array}{c}\text { Forward } \\
\text { label }\end{array}$ & Set & $\begin{array}{l}\mathrm{Tm} \\
\left({ }^{\circ} \mathrm{C}\right)\end{array}$ & At & $R t$ \\
\hline \multirow[t]{2}{*}{ McM527 } & GTCCATTGCCTCAAATCAATTC & HEX & 1 & 55 & 8 & 6.5 \\
\hline & AАACСАСТTGАСТАСТССССАА & & & & & \\
\hline \multirow[t]{2}{*}{ ILSTS005 } & GGAAGCAATTGAAATCTATAGCC & FAM & 1 & 60 & 7 & 6.5 \\
\hline & TGTTCTGTGAGTTTGTAAGC & & & & & \\
\hline \multirow[t]{2}{*}{ SRCRSP9 } & AGAGGATCTGGAAATGGAATC & FAM & 1 & 58 & 7 & 4.5 \\
\hline & GCACTCTTTTCAGCСCTAATG & & & & & \\
\hline \multirow[t]{2}{*}{ OarFCB20 } & GGAAAACCСССАТАTATACСТАTAC & FAM & 2 & 58 & 9 & 7.9 \\
\hline & AAATGTGTTTAAGATTCCATACATGTG & & & & & \\
\hline \multirow[t]{2}{*}{ SRCRSP5 } & GGACTCTACCAACTGAGCTACAAG & FAM & 2 & 53 & 13 & 8.0 \\
\hline & TGAAATGAAGCTAAAGCAATGC & & & & & \\
\hline \multirow[t]{2}{*}{ TGLA53 } & GCTTTCAGAAATAGTTTGCATTCA & HEX & 2 & 55 & 11 & 7.6 \\
\hline & ATCTTCACATGATATTACAGCAGA & & & & & \\
\hline \multirow[t]{2}{*}{ ILSTS011 } & GCTTGCTACATGGAAAGTGC & HEX & 2 & 53 & 11 & 6.6 \\
\hline & CTAAAATGCAGAGCССТССС & & & & & \\
\hline \multirow[t]{2}{*}{ SRCRSP23 } & TGAACGGGTAAAGATGTG & FAM & 3 & 58 & 9 & 8.1 \\
\hline & TGTTTTTAATGGCTGAGTAG & & & & & \\
\hline \multirow[t]{2}{*}{ SPS113 } & ССТССACACAGGCTTCTCTGACTT & FAM & 3 & 60 & 10 & 8.1 \\
\hline & ССTAACTTGCTTGAGTTATTGCCC & & & & & \\
\hline \multirow[t]{2}{*}{ SRCRSP7 } & TCTCAGCACCTTAATTGCTCT & HEX & 3 & 55 & 8 & 6.0 \\
\hline & GGTCAACACTCCAATGGTGAG & & & & & \\
\hline \multirow[t]{2}{*}{ INRA063 } & GACCACAAAGGGATTTGCACAAGC & HEX & 3 & 58 & 13 & 8.5 \\
\hline & AAACCACAGAAATGCTTGGAAG & & & & & \\
\hline
\end{tabular}

$\mathrm{Tm}=$ Annealing temperature; At = Total number of alleles per locus; Rt = Allelic richness over all samples.

Hoffmann, I., P. A. Marsan, S. F. Barker, E. G. Cothran, O. Hanotte, J. A. Lenstra, D. Milan, S. Weigend and H. Simianer. 2004. New MoDAD marker sets to be used in diversity studies for the major farm animal species: recommendations of a joint ISAG/FAO working group. In: 29th International Conference on Animal Genetics. FAO, Meiji University, Tokyo, Japan. 


\section{Statistical analysis}

The absence of linkage between loci was verified using GENEPOP 3.4 (Raymond and Rousset, 1995). The polymorphism parameters were obtained using Excel Microsatellite Toolkit Version 3.1 (http://animalgenomics. ucd.ie/sdepark/ms-toolkit/index.php) and POPGENE 1.31 (Yeh and Boyle, 1997). The F-statistic values (FIT, FIS, and FST; Weir and Cockerham, 1984), together with the allelic richness (AR) of each breed, were estimated with FSTAT 2.9.3 (Goudet, 2001). Nei's standard genetic distance $D_{S}$ (Nei, 1972) and Nei's genetic distance $D_{A}$ (Nei et al., 1983) between breeds were calculated using the DISPAN package. Neighbour-joining (NJ) dendrograms and the Unweighted pair group method with arithmetic mean (UPGMA) were constructed based on $D_{A}$ and $D_{S}$. The robustness of the dendrograms was evaluated using a Bootstrap test of 1,000 resamplings of loci with replacement. Principal component analysis (PCA) was performed to reveal major patterns of genetic variability and clustering of breeds based on allele frequencies using MVSP 3.1 (http://www.kovcomp.com). Based on the genotypes at the 11 microsatellite markers, individual animals were clustered into a given number of populations and assigned probabilistically to clusters inferred with a Bayesian approach implemented by the STRUCTURE software (Pritchard et al., 2000).

\section{RESULTS AND DISCUSSION}

\section{Polymorphism of microsatellite loci}

Results showed that 11 loci were polymorphic. A total of 106 alleles were detected, and the mean number of alleles across the 11 loci was 9.6. The number of alleles per locus (At) ranged from 7 for ILSTS005 and SRCRSP9 to 13 for INRA063 and SRCRSP5, which is greater than that reported by FAO-ISAG (Table 2). Allelic richness over all samples per locus (Rt) was measured at between 4.5 (SRCRSP9) and 8.5 (INRA063) and the mean allelic richness across 11 loci in our samples was 7.1. Generally, these loci were polymorphic, and the polymorphism information content (PIC) across the 11 loci ranged between 0.545 (SRCRSP7) and 0.778 (INRA063).

The HWE was tested for all breed-locus combinations. Significant $(\mathrm{p}<0.05)$ deviations from a HWE were observed for $13(14.8 \%)$ of 88 breed-locus combinations (data not shown). But no significant ( $p>0.05$ ) deviation from a HWE was detected for either a single locus across all breeds or a single breed across all loci.

\section{Genetic diversity}

There was a high allelic variation found in the Chinese goat breeds for 11 loci. A summary of the identified polymorphisms from all of the meat goat breeds we tested is listed in Table 3. For the Chinese goats, the observed heterozygosity $(\mathrm{Ho})$ ranged from 0.697 to 0.738 with the lowest value found in Tibet goats and the highest in Matou goats. The outgroup Boer goat breed was 0.634 (SD = 0.024).

There were notable differences in the $\hat{H}$ and $A R$ among these breeds (Table 3 ). The unbiased gene diversity $(\hat{H})$ values varied between 0.738 in Tibet goats and 0.781 in Matou goats (mean value: 0.762; SD: 0.014). Allelic richness $(A R)$ was the highest in the Anhui breed $(A R=$ 7.35) and lowest in Tibet $(A R=6.21)$, with a mean of 6.78. Allelic richness $(A R)$ in the Boer was 6.07. For Chinese goat breeds, the mean number of alleles (MNA) among these goat breeds ranges from 6.27 (Tibet) to 7.36 (Anhui).

Table 3. Sampling information and basic parameters for the genetic diversity associated with the 8 meat goat breeds analyzed in this study

\begin{tabular}{|c|c|c|c|c|c|c|c|c|}
\hline \multirow{2}{*}{ Breeds and codes } & \multicolumn{5}{|c|}{ Allelic diversity } & \multicolumn{2}{|c|}{ Genetic diversity } & \multirow{2}{*}{ FIS } \\
\hline & TNA & MNA & $N E A$ & $N P A$ & $A R$ & $\hat{H}(S D)$ & $H o(S D)$ & \\
\hline Tibet goat (TB) & 69 & 6.27 & 3.93 & 2 & 6.21 & $0.738(0.013)$ & $0.697(0.022)$ & $-0.056^{*}$ \\
\hline Guizhou white goat (GZ) & 75 & 6.82 & 4.25 & 3 & 6.82 & $0.764(0.010)$ & $0.711(0.020)$ & $0.071 * *$ \\
\hline Shannan white goat (SN) & 77 & 7.00 & 4.32 & 4 & 6.88 & $0.759(0.016)$ & $0.706(0.021)$ & $0.069 * *$ \\
\hline Yichang white goat (YC) & 73 & 6.64 & 4.20 & 8 & 6.59 & $0.748(0.011)$ & $0.711(0.016)$ & $-0.051 * *$ \\
\hline Matou goat (MT) & 77 & 7.00 & 4.55 & 4 & 6.94 & $0.781(0.014)$ & $0.738(0.020)$ & 0.036 \\
\hline $\begin{array}{l}\text { Changjiangsanjiaozhou } \\
\text { white goat (CSJ) }\end{array}$ & 74 & 6.73 & 4.49 & 2 & 6.64 & $0.774(0.014)$ & $0.723(0.016)$ & $0.066^{* * *}$ \\
\hline Anhui white goat (AH) & 81 & 7.36 & 4.59 & 5 & 7.35 & $0.771(0.011)$ & $0.718(0.021)$ & 0.063 \\
\hline Mean & & & & & 6.78 & $0.762(0.014)$ & $0.715(0.017)$ & \\
\hline Boer goat (BR) & 67 & 6.09 & 4.15 & 3 & 6.07 & $0.734(0.013)$ & $0.634(0.024)$ & $-0.137 * * *$ \\
\hline ALL Mean & & & & & 6.69 & $0.759(0.013)$ & $0.705(0.018)$ & \\
\hline
\end{tabular}

TNA = Total number of alleles; NEA = Number of effective alleles; MNA = Mean number of alleles; AR = Allelic richness; NPA = Number of private alleles; $\hat{\mathrm{H}}$ = Unbiased gene diversity; Ho = Observed heterozygosity; SD =Standard deviation; HWE = Number of loci that deviate from a Hardy Weinberg equilibrium; FIS = Population inbreeding coefficient. ${ }^{* * *} \mathrm{p}<0.001 ;{ }^{* *} \mathrm{p}<0.01 ;{ }^{*} \mathrm{p}<0.05$. 
A total of 31 private alleles (NPA) were amplified in our cohort, 28 unique to Chinese goats and three unique to Boer goats. The NPA of the Yichang goats was particularly high $(N P A=8)$, representing $29 \%$ of the total NPA. Most of the private alleles (26) were at very low frequencies of below $5 \%$. Four unique to Chinese goats and one to a Boer goat showed a frequency that exceeded $5 \%$.

The inbreeding coefficients (FIS) for five Chinese breeds were positive, and three of them (GZ, SN and CSJ) reached significant levels ( $\mathrm{p}<0.01$, Table 3 ). The global FST value of 0.056 for Chinese meat goats in this study was similar to that of the Chinese goats (0.063, Di et al., 2011; 0.054, Li and Valentini, 2004) and the European and Middle Eastern goats (0.069, Canon et al., 2006), but lower than the value of 0.143 of the Southeast Asian goats (Barker et al., 2001).

The relative small number of microsatellites (11 loci) may bring some limitations to the analysis. But in this article, the polymorphism of selected microsatellites was rich and these goat breeds had a relative large sample size. These could reduce the limitations caused by the relative small locus number.

\section{Genetic phylogeny}

Genetic phylogeny was analysed with three methods following that of Peter et al. (2007). Using STRUCTURE 2.1, we determined an optimum $K$ value at 4 following Evanno et al. (2005), who found that an ad hoc quantity based on the second order rate of change of the likelihood function with respect to $K(\Delta K)$ did show a clear peak at the true value of $K$. Figure 1 shows a clear clustering $(K=4)$, which was in accordance with breed types. Tibet goat,

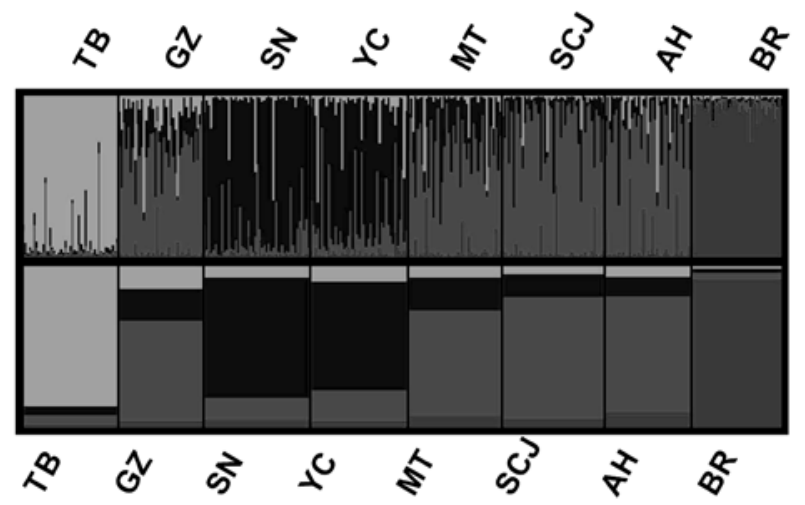

Figure 1. Population structure of eight meat goat breeds displayed with individual (top half of figure) and population (bottom half of figure) Q-matrices at $\mathrm{K}=4$ using STRUCTURE 2.1 following ten independent runs for $2 \leq \mathrm{K} \leq 6$ with $10^{6}$ Markov Chain Monte Carlo repetitions. $\mathrm{TB}=$ Tibet goat; $\mathrm{GZ}=$ Guizhou white goat; $\mathrm{SN}=$ Shannan white goat; YC = Yichang white goat; $\mathrm{MT}=$ Matou goat; $\mathrm{CSJ}=$ Changjiangsanjiaozhou white goat; $\mathrm{AH}=$ Anhui white goat; $\mathrm{BR}=$ Boer goat.

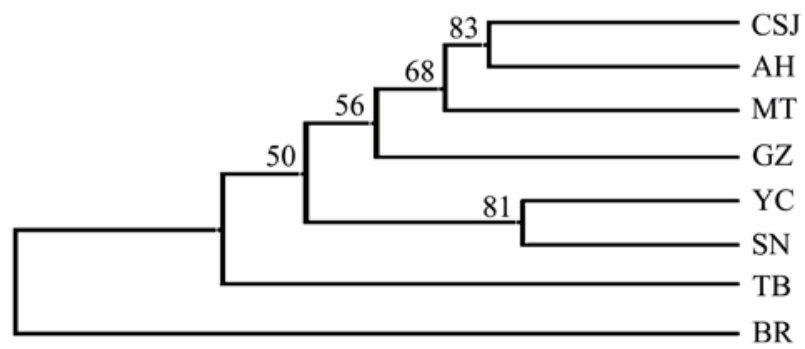

Figure 2. Unweighted pair group method with arithmetic mean (UPGMA) tree based on Nei's DA distances for 8 meat goat breeds. TB = Tibet goat; GZ = Guizhou white goat; $\mathrm{SN}=$ Shannan white goat; $\mathrm{YC}=$ Yichang white goat; $\mathrm{MT}=$ Matou goat; $\mathrm{CSJ}=$ Changjiangsanjiaozhou white goat; $\mathrm{AH}=$ Anhui white goat; $\mathrm{BR}=$ Boer goat.

which belongs to the dual-purpose meat and cashmere goats, was genetically distinct and was the first to separate. The other Chinese goats were then divided into two subclusters: SN and YC in one cluster; and GZ, MT, CSJ and $\mathrm{AH}$ in the other cluster.

In addition, an UPGMA tree was constructed on the basis of the $D_{A}$ genetic distances with relatively high bootstrap values (Figure 2). As expected, the BR was most distinct for other breeds first, and the TB was divided from other Chinese goat breeds. There were two clusters found among the remaining Chinese goats. This grouping pattern was further supported by PCA analysis. Since phylogenetic reconstruction may not easily take into account the effects of admixture between breeds, we performed PCA method to further investigate possible genetic relationships between Chinese goat breeds. The first principal component (PC) explains $31.2 \%$ of the observed genetic variation, and the second and third PCs resolve $23.2 \%$ and $16.0 \%$ of this variation, respectively. A two-dimensional scatter plot for

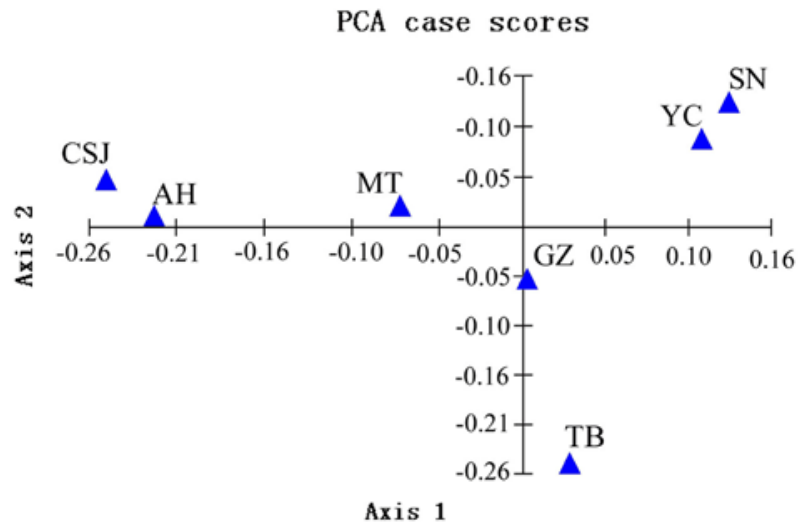

Figure 3. Principal component analysis of 7 Chinese indigenous meat goat breeds. Axis 1 and Axis 2 represent the first two principal factors, respectively. $\mathrm{TB}=$ Tibet goat; GZ = Guizhou white goat; $\mathrm{SN}$ = Shannan white goat; $\mathrm{YC}$ = Yichang white goat; MT = Matou goat; CSJ = Changjiangsanjiaozhou white goat; $\mathrm{AH}=$ Anhui white goat; $\mathrm{BR}=$ Boer goat. 
the Chinese goat breeds we analysed (Figure 3) reveals that they are clustered into several different groups and that reflects the geographical distribution of these breeds, with the secend component corresponding to distributions from east to west, respectively.

Of the Chinese indigenous goats, the Tibetan goat was the most distinct according to structure plot (Figure 1). An early study proposed the Tibetan Plateau to be a place of origin for Chinese goats (Chen et al., 2006). Combined with earlier studies (Chen et al., 2005; Naderi et al., 2008; Wu et al., 2009) and archaeological records, we hypothesize that the Tibetan goat was an ancient breed and might carry unique adaptation alleles. Therefore this breed should be considered as a priority group for conservation and further research.

According to our investigation, the individual exchanges among meat goat breeds for improving meat quantity (Pan et al., 2009; Mao et al., 2010) might have led to a close relationship among meat goat breeds (Figure 1). To maintain the present genetic diversity and structure of these breeds, genetic exchanges between breeds must be controlled on every conservation farm.

\section{ACKNOWLEDGEMENTS}

This work was supported by Genetically Modified Organisms Breeding Major Projects (2009ZX08008-007B), the National High Technology Research and Development (863) in China (SQ2010AA1000688008), Anhui Province Technology Innovation Project Special Program (11Z0101074), Anhui Science and Technology Program (11010302108) and the Technology resources platform of Ministry of Science and Technology (2005DKA21101). We acknowledge all farmers and collaborators who provided and collected the samples for this study.

\section{REFERENCES}

Barker, J. S. F., S. G. Tan, S. S. Moore, T. K. Mukherjee, J. L. Matheson and O. S. Selvaraj. 2001. Genetic variation within and relationships among populations of Asian goats. J. Anim. Breed. Genet. 118(4):213-233.

Canon, J., D. Garcia, M. A. Garcia-Atance, G. Obexer-Ruff, J. A. Lenstra, P. Ajmone-Marsan and S. Dunner. 2006. Geographical partitioning of goat diversity in Europe and the Middle East. Anim. Genet. 37(4):327-334.

Chen, S. Y., Y. H. Su, S. F. Wu, T. Sha and Y. P. Zhang. 2005. Mitochondrial diversity and phylogeographic structure of Chinese domestic goats. Mol. Phylogenet. Evol. 37(3):804-814.

Chen, S. L., B. Fan, B. Liu, M. Yu, S. H. Zhao, M. J. Zhu, T. A. Xiong and K. Li. 2006. Genetic variations of 13 indigenous Chinese goat breeds based on cytochrome b gene sequences. Biochem. Genet. 44(3):89-99.

Di, R., S. M. Farhad Vahidi, Y. H. Ma, X. H. He, Q. J. Zhao, J. L.
Han, W. J. Guan, M. X. Chu, W. Sun and Y. P. Pu. 2010. Microsatellite analysis revealed genetic diversity and population structure among Chinese cashmere goats. Anim. Genet. doi: 10.1111/j.1365-2052.2010.02072.x

Evanno, G., S. Regnaut and J. Goudet. 2005. Detecting the number of clusters of individuals using the software STRUCTURE: a simulation study. Mol. Ecol. 14(8):2611-2620.

Goudet, J. 2001. FSTAT, a program to estimate and test gene diversities and fixation (version 2.9.3.2). Available at: http://www2.unil.ch/popgen/softwares/fstat.htm

Li, X., Y. Zhang, S. Chen and F. Zeng. 1997. Study on the mtDNA RFLP of goat breeds. Zool. Res. 18(4):421-428.

Li, X. L., Y. P. Zhang, S. O. Chen, F. T. Zeng, X. P. Qiu and X. M. Liu. 2000. Study on the random amplified polymorphic DNA of main native goat breeds in China. Acta. Vet. Zoot. Sin. 31(5):416-422.

Li, X. L. and A. Valentini. 2004. Genetic diversity of Chinese indigenous goat breeds based on microsatellite markers. J. Anim. Breed. Genet. 121(5): 350-355.

Mao, Y. Y., H. D. Luo, H. H. Guo, X. Z. Zhang, Z. W. Wang, J. Li, D. C. Wang, Y. C. Zhang and H. Tian. 2010. Analysis on Microsatellite DNA Polymorphism and the Prediction of Heterosis among Boer Goat and Shanxi Local Goats. China. Herbi. 4:5-8.

Naderi, S., H. R. Rezaei, F. Pompanon, M. G. B. Blum, R. Negrini, H. R. Naghash, B. Özge, M. Mashkour, O. E. Gaggiotti, A. M. Paolo, A. Kence, J. D. Vigne and P. Taberlet. 2008. The goat domestication process inferred from large-scale mitochondrial DNA analysis of wild and domestic individuals. Proc. Natl. Acad. Sci. USA. 105(46):17659-17664.

Nei, M. 1972. Genetic distances between populations. Am. Nat. 106:283-292.

Nei, M., R. Tajima and Y. Tateno. 1983. Accuracy of estimated phylogenetic trees from molecular data. J. Mol. Evol. 19(2): 153-170.

Pan, J. W., X. W. Liang, Q. H. Liu and R. H. Bao. 2009. Analysis of genetic diversity in Fujian local goat and Boer goat by using microsatellite markers. J. Fujian. Agric. Forest. Univ. 38(2): 144-149.

Peter, C., M. Bruford, T. Perez, S. Dalamitra, G. Hewitt and G. Erhardt. 2007. Genetic diversity and subdivision of 57 European and Middle-Eastern sheep breeds. Anim. Genet. 38(1):37-44.

Raymond, M. and F. Rousset. 1995. GENEPOP (version 1.2): population genetics software for exact tests and ecumenicism. J. Hered. 86(3):248-249.

Sambrook, J. and D. Russell. 2001. Molecular cloning: A laboratory manual. 3rd ed. Cold Spring Harbor Laboratory Press, Cold Spring Harbor, NY, USA.

Tu, Y. R., Y. Jiang, Z. Y. Han and W. Q. Feng. 1989. Sheep and goat breeds in China, Shanghai: Shanghai Scientific and Technical Publishing House, Shanghai.

Weir, B. S. and C. C. Cockerham. 1984. Estimating F-statistics for the analysis of population structure. Evolution 38(6):13581370.

Wu, Y. P., W. J. Guan, Q. J. Zhao, X. H. He, Y. B. Pu, J. H. Huo, J. F. Xie, J. L. Han, S. Q. Rao and Y. H. Ma. 2009. A fine map for maternal lineage analysis by mitochondrial hyperviable region 
in 12 Chinese goat breeds. J. Anim. Sci. 80(4):372-380.

Yeh, F. C. and T. J. B. Boyle. 1997. Population genetic analysis of codominant and dominant markers and quantitative traits. Belg. J. Bot. 129(2):157.
Zhao, Y. J., H. Z. Xu, L. X. Shi and J. H. Zhang. 2011. Polymorphisms in Exon 2 of MHC class II DRB3 gene of 10 domestic goats in southwest China. Asian-Aust. J. Anim. Sci. 24(6):752-756. 